\title{
Idade ao Primeiro Parto e Intervalo de Partos de Cinco Grupos Genéticos Holandês x Gir no Brasil
}

\author{
Olivardo Facó ${ }^{1}$, Raimundo Nonato Braga Lôbo², Raimundo Martins Filho ${ }^{3}$, Francisco de Assis \\ Melo Lima ${ }^{4}$
}

\begin{abstract}
RESUMO - Tendo em vista a grande importância dos bovinos mestiços Holandês x Gir (H x G) nos sistemas de produção de leite no Brasil e a íntima relação entre a reprodução e a produtividade destes sistemas, foram obtidos registros de partos e datas de nascimento junto à Associação Brasileira dos Criadores de Girolando, no intuito de avaliar o desempenho reprodutivo de vários grupos genéticos HxG. Os dados, num total de 2.600 registros de idade ao primeiro parto (IPP) e 3.763 de intervalos de partos (IDP), foram analisados por meio do procedimento GLM do pacote estatístico SAS (1999). As comparações do desempenho dos grupos genéticos foram feitas por meio de modelos classificatórios incluindo o efeito de grupo genético. Foram feitas estimativas dos efeitos genéticos, isto é, da diferença aditiva entre Holandês e Gir, do efeito de dominância e do efeito epistático aditivo x aditivo, utilizando-se modelos de regressão. O grupo meiosangue apresentou desempenho superior, ou seja, menores IPP e IDP. Foi observada tendência de elevação do IDP com o aumento da proporção de genes da raça Holandesa. O efeito de dominância influenciou significativamente as duas características estudadas, enquanto o efeito de interação epistática do tipo aditivo x aditivo influenciou significativamente apenas a IPP. Os resultados indicaram que a perda de interações epistáticas favoráveis contribuiu para a alta IPP no grupo 5/8 Holandês.
\end{abstract}

Palavras-chave: cruzamentos, efeitos epistáticos, Girolando, heterose, desempenho reprodutivo

\section{Age at First Calving and Calving Interval of Five Holstein x Gir Genetic Groups In Brazil}

\begin{abstract}
Reproduction efficiency of Holstein x Gir crossbred animals in Brazilian dairy farms were evaluated using data provided by the Brazilian Association of Girolando. A total of 2,600 records of age at first calving (IPP) and 3,763 records of calving intervals (IDP) were analyzed using the SAS ${ }^{\circledR}$ GLM procedure. Estimates of genetics effects: additive difference between Holstein and Gir breeds, dominance and additive $\mathrm{x}$ additive epistatic effects were obtained by regression models including genetic groups to model the performance of crossbred groups. The genetic group $1 / 2$ showed better performance: lower averages for IPP and IDP than the other groups. It was observed a trend of increasing IDP as the proportion of Holstein genes increased. The dominance effect influenced significantly both traits, while the additive $\mathrm{x}$ additive epistatic effects significantly influenced only IPP. The results indicated that loss of favorable epistatic interactions contributed to high IPP average in the $5 / 8$ group.
\end{abstract}

Key Words: crossbreeding, epistatic effects, Girolando, heterosis, reproductive efficiency

\section{Introdução}

Na tentativa de melhorar a produtividade dos sistemas de produção de leite sob condições tropicais, tem-se utilizado em larga escala o cruzamento de raças zebuínas, que apresentam excelente adaptação às condições tropicais, com raças de origem européia, especializadas em produção de leite. Isso ocorre, geralmente, em razão de sérios problemas de adaptação dos animais puros de raças especializadas sob condições tropicais, como estresse térmico, baixa qualidade dos alimentos, manejo inadequado, parasitas, entre outros, que, em muitos casos, inviabilizam o sistema de produção.
Entre os fatores que mais influenciam a produtividade em rebanhos leiteiros, destaca-se a eficência reprodutiva, especialmente em rebanhos mestiços Europeu $\mathrm{x}$ Zebu, nos quais geralmente ocorrem lactações mais curtas nos animais dos grupos genéticos com menor proporção de genes da raça Holandesa (Facó et al., 2002). Estas lactações mais curtas precisam ser compensadas com menores intervalos de partos para que o período seco não seja excessivamente extenso.

Outro fator relacionado à eficência reprodutiva é a idade ao primeiro parto, indicativo de precocidade sexual e, portanto, de elevada importância econômica,

\footnotetext{
${ }^{1}$ Pesquisador Embrapa Caprinos, Doutorando em Zootecnia - PDIZ/UFC; Fazenda Três Lagoas - Estrada Sobral Groaíras, Km 4, Caixa Postal D10 - CEP 62011-970 - Sobral - CE (faco@cnpc.embrapa.br; ofaco@uol.com.br).

2 Pesquisador Embrapa Caprinos - Sobral - CE (Iobo@cnpc.embrapa.br). Bolsista CNPq.

${ }^{3}$ Professor colaborador PDIZ/UFC e Bolsista DCR/CNPq/FAPEPI/UFPI - Fortaleza - CE (martins@ufc.br).

${ }^{4}$ Professor do Departamento de Zootecnia - CCA - UFC (mlima@ufc.br).
} 
uma vez que marca o início da vida produtiva de uma fêmea leiteira e influencia os custos de reposição das matrizes (Lemos et al., 1992).

No Brasil, a maior parte da produção de leite é obtida com a utilização de animais mestiços zebuínos, sobretudo os Holandês x Gir. Considerando a importância deste tipo racial no panorama da produção de leite nacional, em 1989, o Ministério da Agricultura, juntamente com as associações representativas, traçou as normas (Brasil, 1992) para a formação da Raça Girolando - Gado Leiteiro Tropical (5/8 Holandês + 3/8 Gir - bi-Mestiço). Para criar uma ampla base genética para a formação da raça sintética, a princípio, animais de vários grupos genéticos Holandês x Gir estão sendo controlados. Assim, a partir dos dados de controle de partos, fornecidos pela Associação Brasileira dos Criadores de Girolando, torna-se possível o estudo do desempenho reprodutivo dos vários grupos genéticos.

Este trabalho foi realizado com o objetivo de comparar o desempenho reprodutivo de cinco grupos genéticos Holandês x Gir, por meio da análise dos diversos fatores genéticos e de ambiente que influenciam a expressão das características idade ao primeiro parto (IPP) e intervalo de partos (IDP) e, a partir dos resultados, contribuir para maior conhecimento acerca das potencialidades dos diversos sistemas de cruzamento para melhorar o desempenho reprodutivo de rebanhos leiteiros sob condição tropical.

\section{Material e Métodos}

Foram obtidos registros de partos e datas de nascimento junto à Associação Brasileira dos Criadores de Girolando, a partir dos quais foi composto o arquivo de dados que possibilitou o cálculo das idades ao primeiro parto (IPP) e dos intervalos de parto (IDP).

As idades ao primeiro parto foram calculadas pela diferença em dias entre a de nascimento e a data do primeiro parto, enquanto os intervalos de partos foram obtidos pela diferença em dias entre dois partos consecutivos.

As análises descritivas dos dados foram realizadas por meio dos procedimentos estatísticos contidos no programa SAS (1999), verificando-se as restrições, as limitações e a consistência das informações.

O total de registros de idade ao primeiro parto e de intervalo de partos era inicialmente de 2.799 e 4.058 , respectivamente. Foram excluídos das análises os registros considerados atípicos, ou seja, com IPP $<600$ ou $>1460$ e IDP $<300$. Foram ainda excluídos os registros provenientes de fazendas com menos de cinco observações, restando 2.600 e 3.763 registros de IPP e IDP, respectivamente. Os registros de IPP corresponderam a animais nascidos entre 1989 e 1995, enquanto os registros de IDP, a partos ocorridos entre 1991 e 1997.

Mais de $90 \%$ dos registros estudados foram provenientes de fazendas localizadas no estado de Minas Gerais.

Os dados foram analisados pelo método dos quadrados mínimos por meio do procedimento GLM(SAS, 1999). Para o estudo dos IDPs, foram definidos os seguintes modelos:

\section{Modelo 1}

$\mathrm{Y}_{\mathrm{jklmno}}=\mathrm{m}+\mathrm{gx}_{1 \mathrm{j}}+\mathrm{dx}_{2 \mathrm{j}}+\mathrm{gg}_{3 \mathrm{j}}+\mathrm{MP}_{\mathrm{k}}+\mathrm{AP}_{1}+\mathrm{OP}_{\mathrm{m}}$ $+\mathrm{FAZ}_{\mathrm{n}}+\mathrm{e}_{\mathrm{jklmno}}$

Modelo 2

$\mathrm{Y}_{\mathrm{jklmno}}=\mathrm{m}+\mathrm{gx}_{1 \mathrm{j}}+\mathrm{dx}_{2 \mathrm{j}}+\mathrm{MP}_{\mathrm{k}}+\mathrm{AP}_{1}+\mathrm{OP}_{\mathrm{m}}$ $+\mathrm{FAZ}_{\mathrm{n}}+\mathrm{e}_{\mathrm{jklmno}}$

\section{Modelo 3}

$\underset{+\mathrm{e}_{\mathrm{jklmno}}}{\mathrm{Y}_{\mathrm{jklmno}}}=\mathrm{m}+\mathrm{GG}_{\mathrm{j}}+\mathrm{MP}_{\mathrm{k}}+\mathrm{AP}_{1}+\mathrm{OP}_{\mathrm{m}}+\mathrm{FAZ}_{\mathrm{n}}$

em que $\mathrm{Y}_{\mathrm{jklmno}}=$ intervalo de partos; $\mathrm{m}=$ intercepto; $\mathrm{GG}_{\mathrm{j}}=$ efeito do jésimo grupo genético $(1 / 4,1 / 2$, $5 / 8,3 / 4$ e $=7 / 8$ de genes holandês $) ; \mathrm{MP}_{\mathrm{k}}=$ efeito do $\mathrm{k}^{\text {ésimo }}$ mês de parto; $\mathrm{AP}_{1}=$ efeito do $1^{\text {ésimo ano }}$ de parto; $\mathrm{OP}_{\mathrm{m}}=$ efeito da $\mathrm{m}^{\text {ésima }}$ ordem de parição $\left(1^{\mathrm{a}}\right.$. à $9^{\mathrm{a}}$.); $\mathrm{FAZ}_{\mathrm{n}}=$ efeito da $\mathrm{n}^{\text {ésima }}$ fazenda; $\mathrm{g}=$ diferença aditiva entre as raças (Holandês e Gir); $\mathrm{x}_{1 \mathrm{j}}=$ proporção esperada de genes Holandês nos indivíduos do jésimo grupo genético; $\mathrm{d}=$ efeito de dominância; $x_{2 j}=$ proporção esperada de locos ocupados por um alelo de cada raça nos indivíduos do jésimo grupo genético; gg = efeito epistático aditivo $x$ aditivo; $x_{3 j}=$ fração esperada de efeitos epistáticos do tipo aditivo $\mathrm{x}$ aditivo nas raças parentais recuperadas nos indivíduos do jésimo grupo genético; $\mathrm{e}_{\mathrm{jklmno}}=$ efeito residual.

Todos os efeitos, exceto residual (e), foram considerados fixos.

Para a característica IPP, os modelos foram os mesmos utilizados para a IDP, com as seguintes modificações: (1) em vez de mês e ano de parto, foram considerados mês e ano de nascimento, respectivamente, e (2) não foi incluído o efeito da ordem de parição. 
Os valores utilizados para $\mathrm{x}_{1}, \mathrm{x}_{2}$ e $\mathrm{x}_{3}$ encontram-se na Tabela 1 e sua derivação foi realizada segundo Dickerson (1973) e Eisen (1989), citados por Lemos et al. (1992). Em função das diferentes formas de se obterem animais $5 / 8$ e da indisponibilidade de informação acerca do genótipo dos pais, o valor de $\mathrm{x}_{2}$ utilizado para este grupo genético foi de 0,57333 (média de 0,75 ; $0,50$ e 0,47$)$, conforme sugerido por Martinez et al. (1988).

A comparação do desempenho dos grupos genéticos para as duas características foi feita utilizando-se o modelo 3. Em razão do pequeno número de registros de animais dos grupos genéticos $7 / 8$ e Holandês $(\geq 15 /$ 16 ), esses animais foram agrupados como grupo genético $\geq 7 / 8$.

Segundo Robison et al. (1981), o uso de um modelo que contenha o efeito de grupo genético contabilizaria todos os efeitos genéticos, inclusive aqueles não-lineares e os epistáticos. Portanto, a comparação dos resultados obtidos pelo modelo 3 com aqueles obtidos pelos modelos de regressão 1 e 2 deve gerar informação acerca da importância dos efeitos genéticos não-lineares e epistáticos.

A qualidade do ajuste promovido pelos modelos 1 e 2 foi avaliada por meio do teste $F$, em que o numerador foi a diferença entre a soma de quadrados do resíduo dos modelos de regressão 1 ou 2 e a soma

Tabela 1 - Proporções esperadas de genes da raça Holandesa $\left(x_{1}\right)$, de locos ocupados por um alelo de cada raça $\left(x_{2}\right)$ nos diversos grupos genéticos estudados e de efeitos epistáticos aditivo $x$ aditivo das raças parentais recuperados nos mestiços $\left(\mathrm{x}_{3}\right)$

Table 1 - Expected proportions of Holstein genes $\left(x_{1}\right)$, expected proportion of loci with one gene of each breed $\left(x_{2}\right)$ in different genetic groups and expected proportion of additive $x$ additive epistatic effects in parental breeds that are recovered in crossbreds $\left(x_{3}\right)$

\begin{tabular}{lccc}
\hline $\begin{array}{l}\text { Grupo genético } \\
\text { Genetic group }\end{array}$ & $\mathrm{x}_{1}$ & $\mathrm{x}_{2}$ & $\mathrm{x}_{3}$ \\
\hline $1 / 4$ & 0,25000 & 0,50000 & 0,62500 \\
$1 / 2$ & 0,50000 & 1,00000 & 0,50000 \\
$5 / 8$ & 0,62500 & 0,57333 & 0,53125 \\
$3 / 4$ & 0,75000 & 0,50000 & 0,62500 \\
$7 / 8$ & 0,87500 & 0,25000 & 0,78125 \\
$\mathrm{H}^{2}$ & $1,00000^{*}$ & $0,00000^{*}$ & $1,00000^{*}$
\end{tabular}

${ }^{1}$ Expresso como proporção esperada de genes da raça Holandesa.

1 Expressed as expected proportion of genes from Holstein breed.

${ }^{2}$ Animais com proporção esperada de genes da raça holandesa $\geq 15 / 16$.

${ }^{2}$ Animal with expected proportion of genes from Holstein breed $\geq 15 / 16$.

Valor assumido para as análises.

* Assumed values in the analysis. de quadrados do resíduo do modelo 3, dividida pela diferença entre os graus de liberdade do resíduo do modelo de regressão considerado e os graus de liberdade do resíduo do modelo 3 , enquanto o denominador foi o quadrado médio residual do modelo 3 (Robison et al., 1981).

As estimativas para os efeitos genéticos $(\mathrm{g}, \mathrm{d}$ e $\mathrm{gg}$ ) foram produzidas a partir do modelo (1 ou 2) que apresentou melhor ajuste quando comparado ao modelo 3 .

\section{Resultados e Discussão}

Todos os efeitos de ambiente incluídos nos modelos 1,2 e 3 influenciaram significativamente $(P<0,05)$ as características estudadas e não são discutidos aqui, pois foram incluídos apenas para aumentar a precisão das análises genéticas.

$\mathrm{Na}$ Tabela 2 são apresentadas as médias estimadas pelo método dos quadrados mínimos para cada grupo genético. O grupo genético $1 / 2$ teve desempenho superior, isto é, menor IPP que os demais, exceto o grupo genético $\geq 7 / 8$ de genes holandês. Ainda para IPP, o grupo 5/8 apresentou desempenho inferior aos demais grupos, exceto ao $1 / 4$. As vacas do grupo 3/4 apresentaram IPPs intermediárias, tendo o desempenho inferior às meio-sangue, mas semelhante às do grupo $\geq 7 / 8$.

Esses resultados confirmam aqueles encontrados por Lemos et al. (1992), em que as F1 tiveram primeiro parto mais jovens e as $5 / 8$ em idade mais avançada. Rege et al. (1994), estudando o desempenho de animais mestiços Jersey x Ghana Shorthorn (Bos taurus) e Jersey x Sokoto Gudali (Bos indicus), observaram que animais $\mathrm{F}_{1}$ apresentaram menores idades ao primeiro parto que os puros (Ghana Shorthorn ou Sokoto Gudali), porém, ao contrário do observado neste estudo, os animais F1 apresentaram IPPs semelhantes às dos animais produzidos por retrocruzamento (3/4 de genes da Raça Jersey).

Para a característica IDP, o grupo genético 1/2 apresentou desempenho superior, ou seja, menor IDP, aos grupos $3 / 4$ e $\geq 7 / 8$, porém, semelhante aos grupos $1 / 4$ e $5 / 8$. O grupo $\geq 7 / 8$ apresentou desempenho inferior aos demais, exceto ao $5 / 8$, enquanto o $3 / 4$ não diferiu dos grupos $1 / 4$ e 5/8. Verificou-se tendência de elevação do IDP à medida que aumentou a participação de genes da raça Holandesa. Esta tendência está provavelmente ligada à tendência de maior produção 
Tabela 2 - Médias por quadrados mínimos (LSM), erros-padrão (SE) e número de observações (n) para as características idade ao prrimeiro parto (IPP) e intervalo de partos (IDP), de acordo com o grupo genético

Table 2 - Least square means (LSM), standard errors (SE) and number of observations (n) for age at first calving (IPP) and calving interval (IDP), according to genetic group

Grupo genético

Genetic group

Característica

Trait

\begin{tabular}{|c|c|c|c|c|c|c|}
\hline & \multicolumn{3}{|c|}{$\begin{array}{l}\operatorname{IPP}(\text { dia }) \\
\quad(\text { day })\end{array}$} & \multicolumn{3}{|c|}{$\begin{array}{l}\text { IDP (dia) } \\
\quad(\text { day })\end{array}$} \\
\hline & $\mathrm{n}$ & LSM & $\mathrm{SE}$ & $\mathrm{n}$ & LSM & $\mathrm{SE}$ \\
\hline $1 / 4$ & 54 & $1.041,71^{b c}$ & 19,13 & 219 & $413,02^{\mathrm{ab}}$ & 7,57 \\
\hline $3 / 4$ & 1.256 & $1.025,82^{\mathrm{b}}$ & 5,24 & 1.286 & $418,60^{\mathrm{b}}$ & 4,58 \\
\hline
\end{tabular}

Médias com letras iguais na mesma coluna não diferem estatisticamente $(P>0,05)$ pelo teste t.

Means with the same letter in a column do not differ $(P>0.05)$ by $t$ test.

de leite dos grupos genéticos com maior proporção de genes holandeses (Facó et al., 2002).

Madalena et al. (1990) observaram diferenças de IDP entre seis grupos genéticos Holandês x Guzerá apenas no primeiro intervalo de partos, em que os animais 5/8 apresentaram menores IDP's. No entanto, esses autores destacaram que esse bom desempenho reprodutivo dos $5 / 8$ não foi suficiente para compensar a baixa produção de leite exibida por esses animais.

Por outro lado, Guimarães et al. (2002) não observaram diferença significativa quanto IDP de vários grupos genéticos Holandês x Gir, variando desde o Gir puro até o Holandês puro por cruza. Também Lemos et al. (1997), comparando estratégias de cruzamentos, como $\mathrm{F}_{1}, 5 / 8$ bi-mestiça, rotacionado com repetição do Holandês e absorção pelo Holandês, e Madalena et al. (1983), comparando o desempenho de animais 3/4, 7/8 e Holandês puro, observaram IDPs semelhantes.

Rege et al. (1994), estudando o desempenho de animais mestiços Jersey x Ghana Shorthorn, observaram que animais $\mathrm{F}_{1}$ apresentaram menores intervalos de partos que animais puros Ghana Shorthorn e 3/4 Jersey, mas não observaram diferenças significativas entre animais com proporções genéticas semelhantes no cruzamento Jersey x Sokoto Gudali.

Na Tabela 3 estão apresentadas as comparações dos ajustes dos modelos epistático e aditivo-dominante em relação àquele obtido pelo modelo classificatório para as duas características.

Verificou-se que para a IPP o modelo aditivodominante não ajustou adequadamente os dados, uma vez que a variação adicional explicada pelo modelo classificatório foi estatisticamente significativa $(\mathrm{P}<0,01)$. O modelo epistático, no entanto, garantiu um ajuste tão eficiente quanto o modelo classificatório que inclui o efeito de grupo genético.

Lemos et al. (1992) encontraram resultado semelhante sob baixo nível de manejo, porém, sob alto nível manejo, verificaram que tanto o modelo aditivo-dominante quanto o epistático ajustaram os dados tão bem quanto o modelo classificatório.

Para a característica IDP, tanto o modelo aditivodominante quanto o modelo epistático promoveram ajustes semelhantes àquele obtido pelo modelo classificatório. No entanto, o modelo aditivo-dominante apresentou um ajuste mais próximo do modelo classificatório, evidenciado pelo menor valor de F e pelos menores erros-padrão das estimativas dos efeitos genéticos (Tabelas 3 e 4).

$\mathrm{Na}$ Tabela 4 são apresentadas estimativas da diferença genética aditiva entre as raças Holandês e Gir (g), dos efeitos de dominância (d) e de interações epistáticas do tipo aditivo $\mathrm{x}$ aditivo (gg). Para a IPP, estas estimativas foram geradas pelo modelo epistático, uma vez que o aditivo-dominante não promoveu ajuste adequado. Para a IDP, no entanto, foi utilizado o modelo aditivo-dominante, em razão do menor erropadrão das estimativas e do menor valor de F obtido na comparação com o modelo classificatório.

As interações epistáticas aditiva $\mathrm{x}$ aditiva influenciaram significativamente $(\mathrm{P}<0,001)$ a expressão da idade ao primeiro parto, evidenciando a importância dos efeitos epistáticos para essa característica nas 
Tabela 3 - Comparação do ajuste obtido pelo modelo classificatório (inclui o efeito de grupo genético) com os modelos de regressão 1 (inclui os efeitos epistáticos) e 2 (aditivo-dominante), para as características Idade ao Primeiro Parto (IPP) e Intervalo de Partos (IDP)

Table 3 - Comparison of the adjustment obtained by the classification model (including the effect of genetic group) with regression models 1 (include the epistatic effects) and 2 (additive-dominant), for age at first calving (IPP) and calving interval (IDP)

\begin{tabular}{lcccc}
\hline Característica & Modelo & Graus de liberdade & Soma de quadrados & Quadrado médio \\
Trait & Model & Degrees of freedom & Sum of squares & Mean square
\end{tabular}

\begin{tabular}{|c|c|c|c|c|c|}
\hline \multirow{18}{*}{$\begin{array}{l}\text { Idade ao primeiro parto (IPP) } \\
\text { Age at first calving (IPP) }\end{array}$} & \multirow{9}{*}{$\begin{array}{c}\text { Classificatório } \\
\text { Classification } \\
\text { Regressão } 1 \\
\text { Regression } 1 \\
\text { Diferença } \\
\text { Difference } \\
\text { Erro } \\
\text { Error }\end{array}$} & \multicolumn{4}{|c|}{$\begin{array}{l}\text { Modelo epistático (1) x Modelo classificatório (3) } \\
\text { Epistatic model (1) x Classification model (3) }\end{array}$} \\
\hline & & \multirow[t]{2}{*}{2.498} & \multirow[t]{2}{*}{$33.675 .216,07$} & \multirow[b]{5}{*}{$14.374,17$} & \multirow{8}{*}{$1,07^{\mathrm{ns}}$} \\
\hline & & & & & \\
\hline & & \multirow[t]{2}{*}{2.499} & $33.689 .590,24$ & & \\
\hline & & & \multirow{3}{*}{$14.374,17$} & & \\
\hline & & \multirow[t]{2}{*}{1} & & & \\
\hline & & & & & \\
\hline & & \multirow[t]{2}{*}{2.498} & \multirow[t]{2}{*}{$33.675 .216,07$} & \multirow[t]{2}{*}{$13.480,87$} & \\
\hline & & & & & \\
\hline & & \multirow{2}{*}{\multicolumn{4}{|c|}{$\begin{array}{l}\text { Modelo aditivo-dominante (2) x Modelo classificatório (3) } \\
\text { Additive-dominant model (2) x Classification model (3) }\end{array}$}} \\
\hline & & & & & \\
\hline & \multirow{7}{*}{$\begin{array}{c}\text { Classificatório } \\
\text { Classification } \\
\text { Regressão } 2 \\
\text { Regression } 2 \\
\text { Diferença } \\
\text { Difference } \\
\text { Erro } \\
\text { Error }\end{array}$} & \multirow[b]{3}{*}{2.500} & 2.498 & \multirow[t]{2}{*}{$33.675 .216,07$} & \multirow{7}{*}{$7,91^{* *}$} \\
\hline & & & & & \\
\hline & & & $33.888 .542,83$ & \multirow[b]{3}{*}{$106.663,38$} & \\
\hline & & \multirow{3}{*}{2} & \multirow{3}{*}{$213.326,76$} & & \\
\hline & & & & & \\
\hline & & & & & \\
\hline & & 2.498 & $33.675 .216,07$ & $13.480,87$ & \\
\hline \multirow{17}{*}{$\begin{array}{l}\text { Intervalo de partos (IDP) } \\
\text { Calving interval (IDP) }\end{array}$} & & \multicolumn{3}{|c|}{$\begin{array}{l}\text { Modelo epistático (1) x Modelo classificatório (3) } \\
\text { Epistatic model (1) x Classification model (3) }\end{array}$} & \\
\hline & $\begin{array}{c}\text { Classificatório } \\
\text { Classification }\end{array}$ & 3.665 & 20.117.916,48 & & \\
\hline & Regressão 1 & 3.666 & $20.124 .723,88$ & & \\
\hline & Regression 1 & & & & \\
\hline & Diferença & 1 & $6.807,40$ & $6.807,40$ & $1,24^{\mathrm{ns}}$ \\
\hline & Difference & & & & \\
\hline & Erro & 3.665 & 20.117.916,48 & $5.489,56$ & \\
\hline & Error & & & & \\
\hline & & Mo & lominante (2) $\mathrm{x}$ & o classificató & \\
\hline & & Add & model (2) x Cla & on model (3) & \\
\hline & Classificatório & 3.665 & 20.117.916,48 & & \\
\hline & Classification & & & & \\
\hline & Regressão 2 & 3.667 & 20.127.236,13 & & \\
\hline & Regression 2 & & & & \\
\hline & Diferença & 2 & $9.319,65$ & $4.659,82$ & $0,85^{\mathrm{ns}}$ \\
\hline & Difference & & & & \\
\hline & $\begin{array}{l}\text { Erro } \\
\text { Error }\end{array}$ & 3.665 & 20.117.916,48 & $5.489,56$ & \\
\hline
\end{tabular}

\footnotetext{
** Diferença significativa $(P<0,01) ;$ ns = diferença não-significativa.

** Significant differences $(P<0.01) ; n s=$ not significant difference.
} 
Tabela 4 - Estimativas das diferenças aditivas (g) entre as raças (Holandês - Gir), dos efeitos de dominância (d) e de interação epistática aditiva $x$ aditiva (gg), com os respectivos erros-padrão (SE), de acordo com a característica idade ao primeiro parto (IPP) ou intervalo de partos (IDP)

Table 4 - Estimates of additive differences $(g)$ between the breeds (Holstein - Gir), of dominance effects (d) and of additive $x$ additive epistatic interactions effects (gg), with its respective standard errors (SE) according to trait age at first calving (IPP) or calving interval (IDP)

\begin{tabular}{lcccccc}
\hline $\begin{array}{l}\text { Característica } \\
\text { Trait }\end{array}$ & $\mathrm{g}$ & $\mathrm{SE}$ & $\mathrm{d}$ & $\mathrm{SE}$ & $\mathrm{gg}$ & $\mathrm{SE}$ \\
\hline IPP & $-38,6^{\mathrm{ns}}$ & 39,1 & $-142,7^{* * *}$ & 27,1 & $-286,6^{* * *}$ & 74,6 \\
IDP & $13,21^{\mathrm{ns}}$ & 14,2 & $-15,4^{*}$ & 7,9 & - & - \\
\hline
\end{tabular}

${ }^{*} \mathrm{P}<0,05 ;{ }^{* * *} \mathrm{P}<0,001 ;$ ns $\mathrm{P}>0,05$.

condições deste estudo. Este fato, somadoà inadequação do modelo aditivo-dominante, é indicativo de que o fraco desempenho do grupo genético $5 / 8$ em relação à IPP decorreu não apenas da perda de heterose em relação ao $\mathrm{F}_{1}$, mas também à perda de interações epistáticas favoráveis.

Os sinais negativos das estimativas dos efeitos genéticos (d e gg) para a IPP indicam que tanto o efeito de dominância (d) quanto das interações epistáticas aditiva $\mathrm{x}$ aditiva ( $\mathrm{gg}$ ) foram benéficos no sentido de contribuírem para a redução da idade ao primeiro parto, corroborando os resultados obtidos por Lemos et al. (1992) sob baixo nível de manejo.

Quanto ao IDP, apenas o efeito de dominância (d) foi significativo $(\mathrm{P}<0,05)$, contribuindo para a redução deste intervalo. Embora a diferença genética aditiva entre as raças não tenha apresentado significância, verificou-se uma tendência de elevação do IDP, à medida que se elevou a participação dos genes da raça Holandesa, o que está reforçado pelo sinal positivo da estimativa de g.

Mackinnon et al. (1996) também não encontraram significância dos efeitos de interações epistáticas para o IDP.

Nas condições deste estudo, verifica-se que a heterose para a IPP resultou tanto dos efeitos de dominância quanto dos de interações epistáticas, enquanto, para o IDP, os efeitos de dominância foram os principais responsáveis pela heterose.

\section{Conclusões}

A adequação do modelo genético de regressão aditivo $\mathrm{x}$ dominante deve ser sempre testada, pois esse modelo nem sempre se ajusta de maneira conveniente para os efeitos genéticos, ou seja, nem sempre os efeitos de interação epistáticas, dentre outros efeitos genéticos, são negligenciáveis.

Os resultados observados indicam que a utilização de cruzamentos para produção de animais F1 constitui-se em uma importante alternativa para elevar a precocidade sexual e a fertilidade dos rebanhos leiteiros brasileiros.

O baixo desempenho dos animais 5/8 Holandês demonstra a necessidade de um rigoroso e bem conduzido processo seletivo durante a formação da raça Girolando. Embora sejam características cujas herdabilidades variam de moderada a baixa magnitude, sendo esperado pouco ganho genético, sua elevada importância econômica justifica adequada atenção.

\section{Agradecimento}

À Associação Brasileira dos Criadores de Girolando, que cedeu atenciosamente os dados para este estudo e esteve sempre disponível para esclarecimentos.

\section{Literatura Citada}

BRASIL. Departamento Nacional de Produção Agropecuária Coordenação de Produção Animal. Normas para formação da raça Girolando. Brasília: DF, 1992. 31p.

FACÓ, O.; LÔBO, R.N.B.; MARTINS FILHO, R. et al. Análise do desempenho produtivo de diversos grupos genéticos Holandês x Gir no Brasil. Revista Brasileira de Zootecnia, v.31, n.5, p.1944-1952, 2002.

GUIMARÃES, J.D.; ALVES, N.G.; COSTA, E.P. et al. Eficiência reprodutiva e produtiva em vacas das raças Gir, Holandês e cruzadas Holandês x Zebu. Revista Brasileira de Zootecnia, v.31, n.2, p.641-647, 2002.

LEMOS, A.M.; MADALENA, F.E.; TEODORO, R.L. et al. Comparative Performance of six Holstein-Friesian x Guzera grades in Brazil. 5. Age at first calving. Revista Brasileira de Genética, v.15, n.1, p.73-83, 1992.

LEMOS, A.M.; VERNEQUE, R.S.; TEODORO, R.L. et al. Efeito da estratégia de cruzamentos sobre características produtivas e reprodutivas em vacas do sistema mestiço do CNPGL-EMBRAPA. Revista Brasileira de Zootecnia, v.26, n.4, p.704-708, 1997.

MACKINNON, M.J.; THORPE, W.; BAKER, R.L. Sources of genetic variation for milk production in a crossbred herd in the tropics. Animal Science, v.62, p.5-16, 1996.

MADALENA, F.E.; LEMOS, A.M.; TEODORO, R.L. et al. Dairy production and reproduction in Holstein-Friesian and Guzera crosses. Journal of Dairy Science, v.73, p.1872-1886, 1990. 
MADALENA, F.E.; VALENTE, J.; TEODORO, R.L. et al. Produção de leite e intervalo entre partos de vacas HPB e mestiças HPB:Gir num alto nível de manejo. Pesquisa Agropecuária Brasileira, v.18, n.2, p.195-200, 1983.

MARTINEZ, M.L.; LEE, A.J.; LIN, C.Y. Age and Zebu-Holstein additive and heterotic effects on lactation performance and reproduction in Brazil. Journal of Dairy Science, v.71, n.3, p.800-808, 1988.

REGE, J.E.O.; ABOAGYE, G.S.; AKAH, S. et al. Crossbreeding Jersey with Ghana Shorthorn and Sokoto Gudali cattle in a tropical environment: additive and heterotic effects for milk production, reproduction and calf growth traits. Animal Production, v.59, p.21-29, 1994.
ROBISON, O.W.; McDANIEL, B.T.; RINCON, E.J. Estimation of direct and maternal additive and heterotic effects from crossbreeding experiments in animals. Journal of Animal Science, v.52, n.1, p.44-50, 1981.

STATISTICAL ANALYSIS SYSTEMS - SAS. User's guide. Cary: 1999.

Recebido em: 04/02/04

Aceito em: 15/07/05 